\title{
Teaching of English Writing from the Perspective of Embod- ied-cognitive Linguistics, Meta-cognitive Strategy and Corrective Feedback
}

Yu Zhang*

School of Foreign Language, China West Normal University, Nanchong 637001, Sichuan province, China. Email: 3284624944@qq.com

Abstract: Cognitive linguistics has always been an important branch of linguistics, and during 20th century, linguistics experienced three revolutions: Saussure's structuralism revolution, Chomsky's TG revolution, and cognitive functional linguistics' revolution to Joe's revolution. Time to 21st century, Wang Yin, a famous professor in China, put forward an important and revolutionary point about linguistics based on the research of cognitive linguistics and philosophy. He proposed a new concept, Embodied-Cognitive Linguistics, with repairing cognitive linguistics. In addition, writing has always been the focus and difficulty of most Chinese students to study and how to promote their writing is the essential question for teachers to think deeply. Except Embodied-Cognitive Linguistics, this research will also take the point of Meta-cognitive Strategy and corrective feedback theory and then take some suggestions on how to teach writing.

Keywords: Embodied-Cognitive Linguistics; Meta-cognitive Strategy; Corrective Feedback; English Writing; Teaching

\section{Introduction}

Cognitive linguistics is an important branch of linguistics, and in the 20th century, linguistics experienced three revolutions: Saussure's structuralism revolution, Chomsky's TG revolution; and cognitive functional linguistics' revolution to Joe's revolution ${ }^{[1]}$. Time to 21 st century, Wang Yin, a famous professor in China, put forward an important and revolutionary point about linguistics based on the research of cognitive linguistics and philosophy. He presented a new concept, Embodied-Cognitive Linguistics, with repairing cognitive linguistics, and realized the localization of cognitive linguistics. In addition, writing has always been an important part of Chinese students' learning, but it is difficult to teach compare to other English knowledge. Writing as the output of the language is also worthy for teachers to think about, but teachers spent less time on writing, one reason is that some teachers didn't pay attention to writing, and the other is that some teachers didn't find effective writing teaching methods. Thus, this research aims to put forward corresponding writing-teaching strategies under the guidance of Embodied-Cognitive Linguistics proposed by Professor Wang Yin and Meta-cognitive Strategy and corrective feedback theory.

\subsection{Purpose and significance of the article}

The use of English has penetrated into every aspect in people's lives. As a contemporary youth, it is necessary for Chinese students to use English correctly and skillfully. As a language, the main function of English is to convey people's thoughts, while writing, as a form of language output, occupies a significant position in students' study and life. But based on the phenomenon that students' problems in English writing, English teachers of China should focus on

This is an open-access article distributed under the terms of the Creative Commons Attribution Non-Commercial License (http://creativecommons.org/licenses/by-nc/4.0/), which permits unrestricted non-commercial use, distribution, and reproduction in any medium, provided the original work is properly cited. 
writing and take it as a key teaching object. Aiming at the problem of writing, , especially for beginners in the foreign language learning environment, the aim and importance of this research is to point out some main factors that cause their writing problems and then provide some suggestions under the guidance of Embodied-Cognitive Linguistics, Meta-cognitive Strategy and corrective feedback theory.

\section{Related theory}

Aiming at the matter of English writing teaching, this research aims to put forward some strategies for English writing teaching under the guidance of Embodied-Cognitive Linguistics, Meta-cognitive Strategy and corrective feedback theory. And next, this research will give a brief introduction about these three theories.

\subsection{Embodied-cognitive linguistics}

Embodied-Cognitive Linguistics is a new concept of linguistics based on cognitive linguistics and it is the localization of cognitive linguistics. Next, we will focus on the emergence and principle of Embodied-Cognitive Linguistics.

\subsubsection{Source of Embodied-cognitive linguistics}

Wang Yin has made a systematic, in-depth theoretical thinking and active innovation exploration on cognitive linguistics and its empirical philosophy foundation, and then a localized concept of cognitive linguistics was proposed by professor Wang, namely Embodied-Cognitive Linguistics, which is a significant theoretical contribution to cognitive linguistics. The philosophical basis of cognitive linguistics is idealism, while Professor Wang Yin's Embodied-Cognitive Linguistics insists on materialism, inherits and develops cognitive linguistics.

\subsubsection{Principles of Embodied-cognitive linguistics}

Professor Wang Yin pointed out that the core principle of Embodied-Cognitive Linguistics can be summarized as "reality-cognition-language"[2]. It is intended to emphasize the experience of mind and language, indicating that language is not directly connected with the world, and the role of human in this process must go through the "cognitive" link, and language expression indicates human factors everywhere.

\subsubsection{Several main points of Embodied-cognitive linguistics}

Here, we put forward some important viewpoints of Embodied-Cognitive Linguistics which may be useful in resolving issues of English writing teaching.

\subsubsection{Experience view}

The core principle of Embodied-Cognitive Linguistics is reality-cognition-language, indicates that the first point of language acquisition is to obtain experience, experience and perfect in reality from one's own experience and interaction with the surrounding environment. This further reflects the materialistic basis of cognitive linguistics and emphasizes the role of reality. Embodied-Cognitive Linguistics advocates that people first experience perception in situations and thus have a certain basis of real experience, which is equivalent to the input of real experience and matches the output approach of writing. This emphasizes that only on the basis of experience and perception can we have the way of language acquisition and the direction and content of language output.

\subsubsection{Humanism and active perception}

The second key point of Embodied-Cognitive Linguistics is "cognition". This principle emphasizes and highlights the role of people, and it tells us that the students themselves play a crucial part in the perception of reality and the acquisition of language. Firstly, the subject of perception in the real situation is human, and secondly, the subject of language acquisition is human. The real world and the language are not directly related, but are connected through the mediating effect of "people". Language, as the product of human society, is developed on the basis of people's realistic perception of external things and environment, and communication needs. This emphasizes the important role of human and reflects the humanistic view in Embodied-Cognitive Linguistics. People are subjects with subjective initiative, and their active role in language input and output is great, and has a rising trend, which provides us with an enlightenment to solve the problems of English writing teaching, that is arousing students' initiative, and makes students' subjective acceptance and output more important.

2.1.3.3 Language 
Language, as the third point of Embodied-Cognitive Linguistics, is acquired after human experience of reality and human subjective perception. The corresponding form in English writing is the language output. Corresponding to writing teaching is the output of English language knowledge and thoughts.

\subsection{Meta-cognitive strategy}

Meta-cognition was put forward by Fravel in the 1970s. Briefly, Meta-cognition is the cognition of one's own cognitive process. And it is a typical learning strategy, which means to effectively monitor the students' own cognitive processes and results. And meta-cognitive strategy can be divided into three main strategies: planning strategy, monitoring strategy and regulation strategy. It means that students plan their own learning processes and results, students monitor their learning processes and regulate their learning strategies and methods according to their previous learning results.

\subsection{Corrective feedback}

"Corrective feedback refers to the feedback of language errors made by language learners in oral or written output in a second language"[3], which is an important element of the formative assessment process. This theory emphasizes timely, specific, understandable, actionable and timely feedback. Chinese students study English as a foreign language. They have kinds of problems in English writing more or less, therefore English teachers can get relevant correction methods from the corrective feedback theory.

\section{Problem identification}

Before discussion, we must find out problems that exist in English writing and writing teaching. And next, the following part is mainly about these issues.

\subsection{Problems in English writing}

For most Chinese students, English is a foreign language and most of them have never been exposed to English since childhood, and it's no doubt that Chinese students will encounter various problems when they learn it. Here we will focus on some problems that Chinese students often have in English writing.

\subsubsection{Writing anxiety}

Due to the strangeness of foreign language and other reasons, most Chinese students are more or less anxious in English writing, which has become an important factor affecting students' English writing, and English writing anxiety has hindered students' English output to a great extent. However, many teachers do not pay attention to students' writing anxiety, which is the reason why students' writing level has not been improved for a long time. Writing anxiety here mainly refers to students' anxiety and fear of English writing output due to their strangeness and fear of foreign languages and the lack of their own views. For English teachers, in writing teaching, students' anxiety about English writing ought to be the focus of teaching, and the teacher would pay attention to how to reduce writing anxiety, so that other aspects of writing can be taught.

\subsubsection{Inappropriate wiring material}

The determination of writing materials is the primary factor of writing. The appropriateness of writing materials is an important factor for students to write well, while the inappropriateness of writing materials is also a significant factor for students to write hard. There are various sources of composition materials, some from real life, some from hot news, some from textbooks and some from other composition topics. One of the reasons why students cannot write well is that the writing material is out of touch with the actual words. And we often say that good exam is equivalent to half success. This shows the importance of writing material examination, and it can be seen that many students' writing failure come from the improper examination, so the teacher should pay more attention to writing material examination.

\subsubsection{English foundation}

Weak foundation of English is one of the important factors that leads to student' poor writing skills. And weak foundation of English is also the cause of students' writing anxiety. Due to the limited input of basic English knowledge and other knowledge, students are likely to be unable to write well because of the limited or uncertain English vocabu- 
lary, grammar and long sentences. At the same time, due to the limitation of ideas, it is difficult to write a high-level composition for many students, so this is the negative impact of limited input of English knowledge and other subject knowledge on English writing.

\subsubsection{Students' writing motivation}

Students' learning motivation is a main factor that affects learning effect. Similarly, students' English writing motivation is also a factor of students' English writing difficulties. Because of their weak motivation in English writing, students usually will not spend a lot of time on the aspect of learning, and will unconsciously adopt an attitude of rejection when they learn writing. Generally speaking, active learning attitude will bring better learning effect. Therefore, in English writing, teachers should strike to enhance students' learning motivation and writing motivation, so as to improve students' initiative.

\subsection{Problems in writing teaching}

Teachers and students, as the subjects of interaction, play a significant role in the classroom. Students are usually recipients and inquirers of language, while teachers play a leading role in the classroom, and the impact of teachers leading role should not be ignored, students' academic achievements cannot be separated from teachers' teaching. But it can be seen that quite a few English teachers still have some problems in the teaching of English writing.

\subsubsection{Lack of flexibility in teaching}

Writing teaching is not easy, and students' writing level cannot be improved quickly, which is why some teachers spend less time on writing. In addition, the lack of flexibility in teachers' teaching also causes students to be unable to learn the real knowledge. Some teachers, in order to deal with the exam, simply ask students to keep a recitation about model essays, filling fixed sentences or copying the model essays only. These inflexible ways not only lead to students' weak knowledge, but also intensify their inertia. And student's principal role and teachers' leading role in class can't be brought into play.

\subsubsection{Inappropriate assessment}

Comment is a kind of evaluation on the merits and demerits of students' works after the completion of writing. Teachers' comments on students' compositions and problems pointed out are helpful to students' correction. But if the teacher's evaluation method is inappropriate, it will not play a great role in improving students' writing level. For example, teachers' delayed comments, superficial comments or inappropriate ways, will not improve students' writing level in-depth.

\section{Corresponding strategies}

Here, based on the above problems and relevant theories, some corresponding solutions are proposed as follows.

\subsection{Pay attention to students' emotion}

In addition to students' learning method, students' emotion are also the main factor affecting students' learning results. First of all, teachers should help students eliminate their writing anxiety. After negative emotions are eliminated, students will not be afraid of writing, so that they can express themselves better and more fluently and think clearly. Embodied-cognitive linguistics emphasizes the concept of humanism, which suggests that teachers keep a watchful eye on the subjective role of students while teaching, and take the attitude of student-oriented, and it includes the concern of students' learning emotion, therefore the attention to students' emotions is one important factor which is beneficial to writing teaching. In the teaching of English writing, teachers should pay attention to students' anxiety and other negative emotional factors. Teachers should take measures to eliminate or reduce these negative emotional factors, and strengthen positive emotional factors. For example, after paying attention to students' writing anxiety, teachers should not rush to teaching, but find out the causes of students' anxiety, and then take targeted measures, for example, teachers can relieve students' anxiety and rejection of writing through game teaching. Which are important is to create a relaxed environment for students. 


\subsection{Appropriate materials}

After reducing students' anxiety, the appropriateness of writing materials will also affects students' writing achievements. Appropriate writing materials can give students something to say. On the basis of the principle of Embodied-Cognitive Linguistics: "reality-cognition-language", Embodied-Cognitive Linguistics emphasizes "experience", and the materials for writing should be real to students. It tells us that the testers and teachers should focus their writing materials on students' daily life experience, and dig out materials from students' lives, so that students can have something to say and feelings to write. Similarly, teachers can create relevant situations in writing teaching, as far as possible to let students feel "experienced". In addition, this research argues that students can experience extracurricular activities properly and learning from reality is more important. Due to the limited time, teachers can classify the writing materials, extract classic and representative themes for practical experience, so as to carry out "classroom" teaching, improve flexibility and abandon rote teaching method.

\subsection{Improving students' English basis}

The role of students' basic English knowledge in writing cannot be ignored. It is a normal phenomenon that many students find it difficult to write in English or write better English compositions due to the limitation of vocabulary and grammar. This requires teachers to focus on students' basic English level and classify students' common mistakes, so as to make in-depth explanation and training for them. When teaching vocabulary and grammar, teachers should strive to create a relaxed and pleasant atmosphere, such as inserting more games into teaching, so that students can have better sentences in writing after mastering English knowledge.

\subsection{Strengthen students' writing motivation}

One of the reasons why many students spend too much time on writing without promotion is that they lack motivation to write. Teachers should always keep a watchful eye on students' learning motivation and help students adjust their motivation according to the changes of students' motivation. And under the guidance of meta-cognitive theory, teachers can help students learn to self-monitor and standardize the writing process, so that students can learn to plan their own writing before writing, monitor writing problems in writing, and reflect and adjust writing afterwards. Meta-cognitive strategies are applied to the whole process of writing and meta-cognitive strategies are used to adjust the motivation of writing.

\subsection{Change the way of comment}

Teachers' evaluation can also have an impact on students' learning motivation, as well as writing. Improper evaluation methods can arouse students' resentment, thus affecting their writing, and vice versa. It is necessary that teachers should change the way of writing evaluation appropriately. Instead of giving only one score, they should pay attention to student's progress, writing highlights and writing ideas. It is also good to read great compositions aloud in class, and also read some beautiful sentences or praise that are written by students in class, even if the whole article was not very well. This is a way to praise students' writing and keeping them motivated. Teachers should not only pay attention to syntax, but also explore students' writing ideas and pay attention to students' emotions and reasons for their setbacks, do not deny students' value, and guide students' self-regulation after writing.

\subsection{Timely and corrective feedback}

After students' practice, teachers should give timely corrective feedback. And of course, specific feedback and some suggestion are needed. Besides, there can be peer feedback in class, but it is better for teachers to take indirect corrective feedback and pay close attention to students' confidence and enthusiasm, instead of restraining students' enthusiasm. And teachers should try his or her best to adopt feedback methods that students can understand and accept.

\section{Conclusion}


Writing learning is very important in foreign language learning, and good works must be the joint efforts of students and teachers. However, many Chinese teachers and students still have problems in teaching and learning English writing.. Under the guidance of Embodied-Cognitive Linguistics, meta-cognitive strategies and corrective feedback theory, this research proposes corresponding strategies in English writing teaching. This research proposes strategies from the perspective of "experience" and "humanism" emphasized by Embodied-Cognitive Linguistics, from the perspective of self-monitoring and self-regulation of meta-cognitive strategies, and from the perspective of corrective feedback. This research still has lots of deficiency, but I hope it will help writing teaching.

\section{References}

1. Wang Y. The three linguistic revolutions in the 20th century: Academic frontier of embodied-cognitive linguistics. Foreign Language and Literature Research 2015; (02): 2 - 11.

2. Zhang $\mathrm{K}$. The principle of recognition and the relationship among perceiver, reality and language (in Chinese). Journal of PLA University of Foreign Languages 2019; 42(6): 71 - 80.

3. Sheen Y, Ellis R. "Corrective feedback in language teaching". In E. Hinkel (Ed), Handbook of research in second language teaching and learning. New York: Routledge 2011; $593-607$. 